\title{
Estudo da reparação óssea em mandíbula de ratos
}

\author{
JANETE DIAS ALMEIDA*, YASMIN RODARTE CARVALHO**, ROSILE, FERNANDES DA ROCHA**, EMILIA
} ANGELA LOSCHIAVO ARISAWA*

\section{Resumo}

Neste trabalho os autores realizaram estudo histológico da reparação óssea de defeitos realizados em mandíbulas de ratos. Foram utilizados 18 animais, nos quais realizaram-se perfurações trans-ósseas de 4,0 mm de diâmetro na região de ângulo. Os animais foram sacrificados em grupos de três em períodos pós-operatórios de 1, 3, 5, 7, 14 e 28 dias. Após a fixação, os fragmentos das mandíbulas contendo a área da perfuração foram incluídos em parafina e corados pelo HE. Os resultados mostraram neoformação óssea nas margens do defeito a partir de 3 dias, bem como ao redor de algumas esquírolas ósseas. No período final de observação, de 28 dias, não houve total preenchimento do defeito por tecido ósseo.

\section{UNITERMOS}

Regeneração óssea; osteogênese; mandíbula.

ALMEIDA, J.D. et al. Bone repair.study in rat mandible. Pós-Grad. Rev. Fac. Odontol. São José dos Campos, v.3 , n.1, p. , jan./jun. 2000.

\begin{abstract}
In this article the authors realized a histologic study of bone defect reparation in rat mandible. A surgical defect of $4.0 \mathrm{~mm}$ diameter was made in 18 animals. The rats were sacrificed at 1, 3, 5, 7, 14 and 28 days after the surgery. Mandible fragments containing the defect were included in paraffin, submitted to histological procedures and then analyzed at light microscopy. The results showed bone neoformation at the margins of the defect and around the remaining surgical fragments of bone. At the final observation period of 28 days, there was not a total regeneration of the surgical defect that was partially restored by fibrous connective tissue.
\end{abstract}

\section{UNITERMS}

Bone regeneration; mandible; osteogenesis; wound healing.

\footnotetext{
* Aluna do Curso de Pós Graduação em Odontologia - Área de Concentração em Biopatologia Bucal (Nível Doutorado) Faculdade de Odontologia de São José dos Campos - UNESP - 12245-000 - São José dos Campos - SP

** Departamento de Biopatologia e Diagnóstico - Faculdade de Odontologia de São José dos Campos - UNESP - 12245-000 São José dos Campos - SP
} 


\section{INTRODUÇÃO}

O estudo da reparação de defeitos ósseos é muito importante visto ser um desafio para muitos profissionais da área de saúde ${ }^{6,7}$. Os trabalhos relacionados têm sido realizados há anos, com a intenção de adquirir novos conhecimentos que possam auxiliar em cirurgias de reconstrução ${ }^{5}$, reparações ósseas guiadas ${ }^{9}$ e implantes.

Juntamente ao comportamento mecânico excelente, o osso revela um potencial único para regeneração, sendo capaz de reparação de fraturas ósseas sem que seja observada qualquer cicatriz ${ }^{1}$.

O mecanismo deste padrão de reparação é considerado uma recapitulação da osteogênese que ocorre no embrião e durante o período de crescimento ${ }^{1}$.

Para que uma mineralização sem distúrbios ocorra, existem requisitos básicos, como uma concentração adequada de íons cálcio e fosfato, presença de matriz a ser calcificada, agentes de nucleação e controle de agentes reguladores (promotores e inibidores). Além destes, a formação óssea depende de dois pré requisitos indispensáveis: suporte sangüíneo amplo e suporte mecânico ${ }^{1}$.

Tendo em vista o interesse pelo conhecimento da reparação óssea, é importante que se estabeleça, através do estudo de cortes histológicos, como se processa a neoformação óssea em defeitos semelhantes àqueles realizados em procedimentos cirúrgicos.

O objetivo deste trabalho foi estabelecer um modelo experimental para estudo da reparação óssea em mandíbula de rato, investigando, em cortes histológicos, como evolui a reparação óssea em diferentes períodos.

\section{Material e Método}

Foram utilizados 18 ratos (Rattus norvegicus, variação albinus, Wistar), machos, três meses de idade, peso médio de $300 \mathrm{~g}$, mantidos em gaiolas em temperatura ambiente e alimentados com água e ração ad libitum, fornecidos pelo Biotério da Faculdade de Odontologia de São José dos Campos - UNESP. Os animais foram pesados, sedados e anestesiados com solução aquosa $2 \%$ de cloridrato de 2-(2,6-xilidino)-5,6-dihidro-4H-1,3-tiazina (Rompun) associado a ketamina base (Francotar) na proporção de $1: 0,5 \mathrm{~mL}$ administrados lentamente via intramuscular na dose de $0,1 \mathrm{~mL} /$ $100 \mathrm{~g}$ de peso, com seringa descartável. Após a anestesia foi realizada tricotomia próximo ao ângulo da mandíbula. A incisão da pele que recobre o corpo da mandíbula foi feita com lâmina de bisturi $\mathrm{n} \mathrm{Q} 15$ para que fosse possível a divulsão dos tecidos até o osso. Realizou-se então perfuração cirúrgica trans-óssea no ângulo mandibular do lado direito, com broca esférica de aço no 06 montada em motor de baixa rotação, com irrigação de soro fisiológico (cloreto de sódio 0,9\%) estéril. Os tecidos foram reposicionados e a pele foi suturada com fio de nylon 4.0. Os animais foram sacrificados em número de três por grupo, com 1, 3, 5, 7, 14 e 28 dias pós intervenção cirúrgica. As mandíbulas foram removidas, fixadas em formol a $10 \%$ e em seguida descalcificadas. Após a descalcificação, as peças foram hemisseccionadas na região do defeito ósseo. Os fragmentos foram incluídos em parafina perpendicularmente à superfície de corte. Com a finalidade de observar a neoformação óssea em todo o contorno do defeito, alguns fragmentos foram incluídos paralelamente à superfície de corte. Todos os cortes realizados foram corados pelo método da hematoxilina-eosina para análise histológica, em microscópo óptico.

\section{Resultado}

\section{DIA}

Os cortes histológicos mostraram fragmento de mandíbula formada por duas camadas de osso compacto, tábua interna e externa, interpostas por tecido ósseo esponjoso. No interior do osso mandibular observou-se o canal mandibular contendo feixe vásculo-nervoso. A área do defeito cirúrgico trans-ósseo encontrava-se parcialmente preenchida por rede de fibrina contendo hemácias, algumas esquírolas ósseas e fibras musculares estriadas. Nas proximidades do defeito ósseo observou-se edema e escassas células inflamatórias mononucleares no periósteo, além de feixes de fibras musculares estriadas dissociadas por edema e células inflamatórias predominantemente mononucleares. Em alguns cortes foi possível observar raiz dentária (Figura 1). 


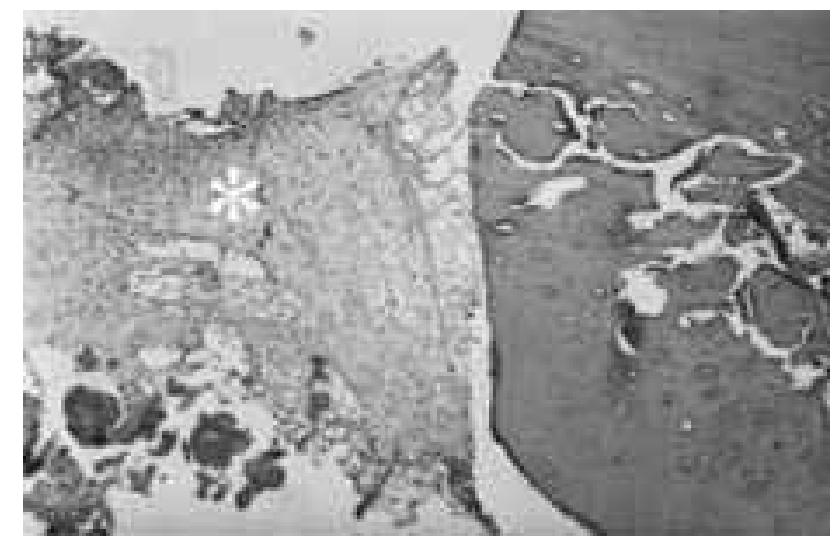

\section{DIAS}

Junto às margens cirúrgicas notou-se a presença de trabéculas ósseas imaturas constituídas por tecido osteóide contendo poucas células e circundadas por células cubóides volumosas, que preenchiam também os espaços medulares. Na região

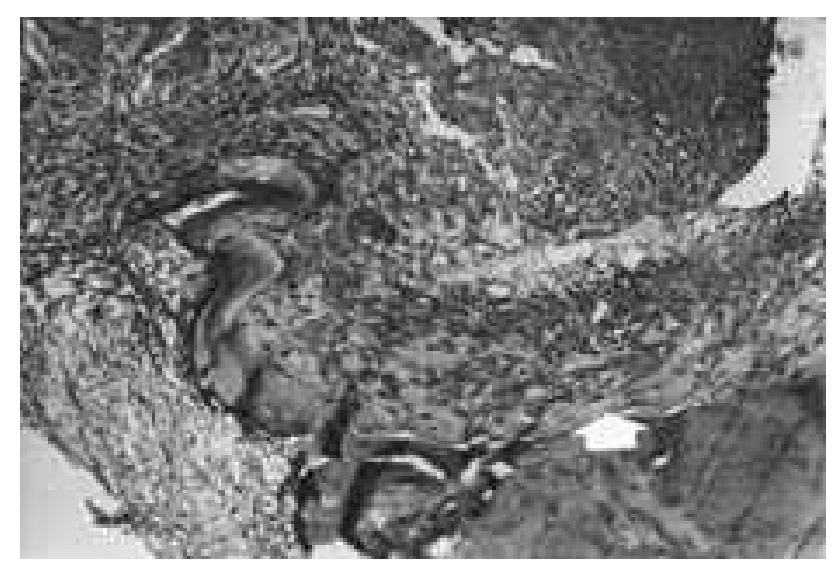

\section{DIAS}

Junto às margens do defeito notou-se uma maior quantidade de tecido ósseo neoformado. No seu

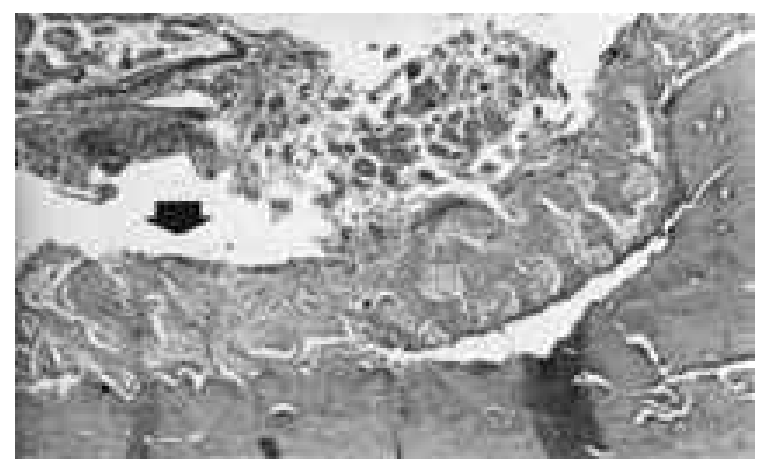

FIGURA 1 - Um dia, área do defeito cirúrgico preenchida por rede de fibrina (\). HE, 100X.

do defeito ósseo cirúrgico observou-se tecido de granulação com células mesenquimais indiferenciadas e vasos sangüíneos neoformados, algumas fibras musculares, além de rede de fibrina. Ao redor de algumas esquírolas ósseas remanescentes observou-se neoformação óssea (Figura 2).

FIGURA 2 - Três dias, trabéculas ósseas imaturas constituídas por tecido osteóide nas margens do defeito cirúrgico (Á). HE, 100X.

interior havia remanescentes de coágulo e tecido de granulação (Figura 3).

FIGURA 3 - Cinco dias, tecido ósseo neoformado nas margens do defeito cirúrgico (Á). HE, 100X. 


\section{DIAS}

Notou-se nas margens do defeito neoformação de trabéculas ósseas nitidamente demarcadas por linha basófila com relação ao tecido ósseo pree-

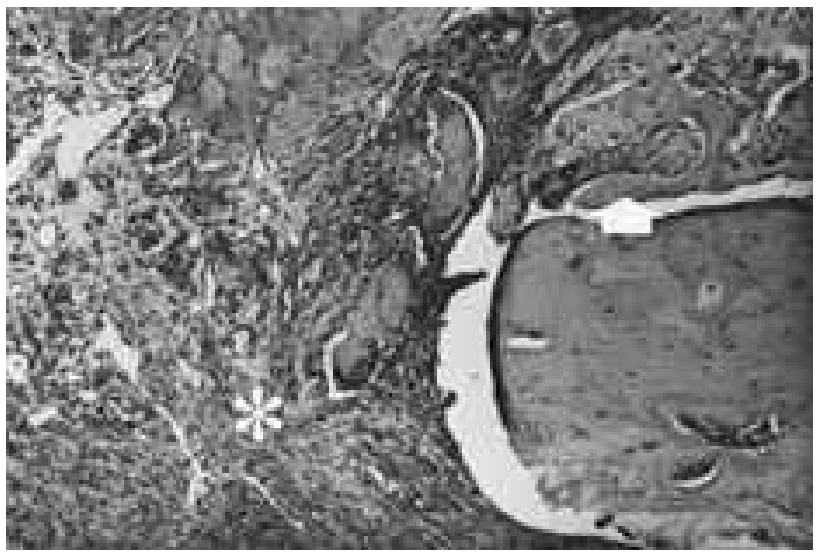

\section{DIAS}

O tecido ósseo neoformado nas margens apresentou-se mais maduro e o defeito ósseo mostrava-se preenchido por tecido conjuntivo jovem com algumas fibras colágenas (Figura 5).

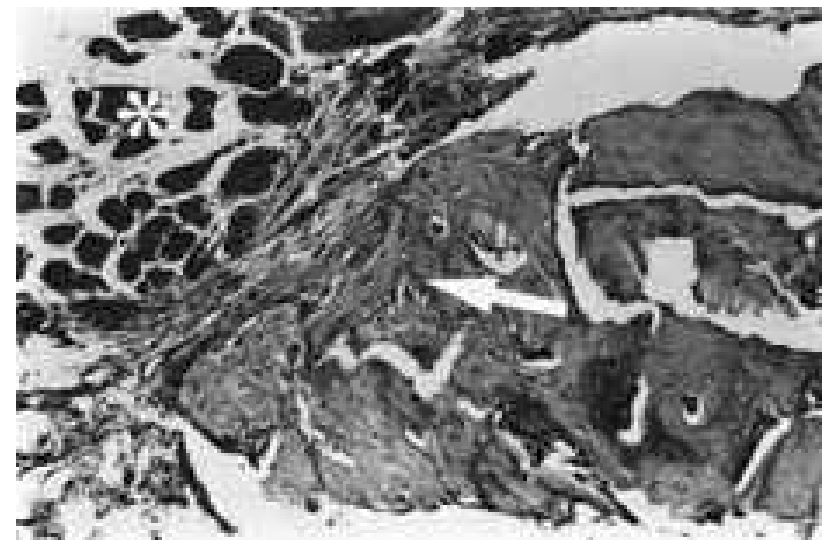

FIGURA 5 - Quatorze dias, área do defeito cirúrgico parcialmente preenchida por tecido muscular $(\backslash)$ e tecido ósseo neoformado na margem do mesmo ( $\ddot{Y})$. HE, 100X. xistente, com fileira de osteoblastos circundando os espaços medulares. Na porção central o tecido de granulação apresentava células gigantes multinucleadas (Figura 4).

FIGURA 4 - Sete dias, área do defeito cirúrgico preenchida por tecido de granulação ( ) com neoformação óssea junto à margem (Á). HE, 100X.

\section{DIAS}

O tecido ósseo das margens mostrou-se mais maduro, porém não houve total preenchimento do defeito cirúrgico. Na porção mais central do mesmo observou-se tecido conjuntivo fibroso e fibras musculares (Figura 6).

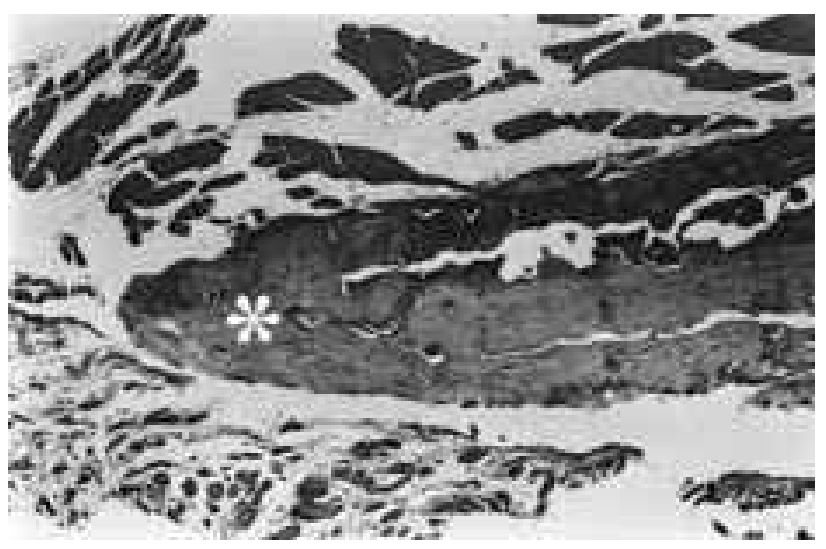

FIGURA 6 - Vinte e oito dias, tecido ósseo maduro preenchendo parte do defeito cirúrgico (\). HE, 100X. 


\section{Dıscussão}

A reparação de defeitos ósseos constitui, há muitos anos, verdadeiro desafio para os cirurgiões dentistas $^{7}$, periodontistas, cirurgiões bucomaxilo faciais, traumatologistas, cirurgiões de cabeça e pescoço, ortopedistas e cirurgiões plásticos ${ }^{6}$. Este desafio tem levado muitos pesquisadores a trabalharem em busca de novas técnicas e dispositivos que auxiliem este processo, levando em consideração a análise seqüencial dos eventos cicatriciais ${ }^{3}$. A mandíbula é um osso que se articula com o crânio, sendo submetida a movimentação constante e a forças compressivas significativas. Assim sendo, a análise da reparação de defeitos ósseos realizados em outros ossos craniofaciais ou ossos longos, pode não ter boa aplicação quando comparados aos processos que podem ocorrer na mandíbula huma$\mathrm{na}^{4}$. Desta forma a utilização do presente modelo experimental para o estudo da reparação óssea em ratos aproxima-se de sua aplicação clínica. Contudo, Hammerle et al. ${ }^{3}$ (1996) consideram que a transposição dos resultados obtidos em modelos experimentais realizados em animais deve feita com precaução, considerando-se as diferenças morfofisiológicas em humanos. Para a realização deste modelo experimental, o defeito ósseo produzido deve ter no mínimo 4,0mm de diâmetro, denominado tamanho crítico, pois um tamanho menor levaria a uma cicatrização espontânea ${ }^{2}$. Neste estudo não foi utilizada barreira mecânica, o que possibilitou o colapso de fibras musculares no interior do defeito ósseo. Alguns estudos experimen-

\section{ReferênCIAs Bibliográficas}

1. BUSER, D. Guided bone regeneration in implant dentistry. Chicago: Quintessence Books, 1994. 265p.

2. DAHLIN, C. et al. Healing of bone defects by guided tissue regeneration. Plast. Reconstr. Surg., v. 81, n. 5, p.672-6, 1988.

3. HÄMMERLE, C.H.F. et al. A novel model system for the study of experimental guided bone formation in humans. Clin. Oral Implants Res., v. 7, n. 1, p. 38-47, 1996.

4. KABAN, L.D., GLOWACKI, J. Induced osteogenesis in the repair of experimental mandibular defects in rats. J. Dent. Res., v. 60, n. 7, p. 1356-64, July 1981.

5. LEW, D. et al. Repair of craniofacial defects with hydroxiapatite cement. J.Oral Maxillofac. Surg., v. 55, n. 12, p. 1441-51,Dec. 1997. tais relatam somente a possibilidade da proliferação de tecido conjuntivo denso, o qual retardaria a reparação óssea ${ }^{6,7}$.

O principal obstáculo para uma reparação óssea satisfatória e a neoformação óssea é que, em contraste à osteogênese, a formação de tecido conjuntivo ocorre rapidamente podendo prejudicar ou impedir totalmente a osteogênese ${ }^{6}$. Rabie et al. ${ }^{8}$ (1996) relatam a necessidade de algum tipo de preenchimento do defeito ósseo com a finalidade de prevenir o colapso de tecido mole no interior do mesmo, além de servir como guia. Além disto, a recomendação da utilização de barreira física para selar locais anatômicos, impedindo o crescimento de tecido conjuntivo para o interior do defeito ósseo é feita por vários autores $2,6,7,8$.

O estudo realizado por Dahlin et al. ${ }^{2}$ (1988) demonstrou que defeitos ósseos descobertos têm reparação atrasada em relação aos revestidos por membrana como barreira mecânica.

Os resultados do presente trabalho mostraram que a reparação dos defeitos ósseos produzidos em mandíbulas de ratos ocorre a partir do tecido ósseo das margens dos mesmos. A neoformação óssea ocorre também ao redor de esquírolas ósseas remanescentes. No entanto, o tamanho do defeito, bem como a utilização de alguma forma de barreira mecânica que impeça a proliferação de tecido conjuntivo em seu interior, são fatores que interferem na completa regeneração do defeito ósseo cirúrgico.

6. LINDE, A. et al. Osteopromotion: a soft-tissue exclusion principle using a membrane for bone healing and bone neogenesis. J. Periodontol., v. 64, n. 11, suppl., p. 1116-28, Nov. 1993.

7. PECORA, G. et al. Bone regeneration with calcium sulfate barrier. Oral Surg. Oral Med. Oral Pathol. Oral Radiol Endod., v.84, n. 4, p. 424-9, Oct. 1997

8. RABIE, A.B.M. et al. The effect of demineralized bone matrix on the healing of intra membranous bone grafts in rabbit skull defects. J. Dent. Res., v. 75, n. 4, p. 1045-51, Apr. 1996.

9. SALATA, L.A., CRAIG, G.T., BROOK, I.M. Bone healing following the use of hydroxiapatite or ionomeric bone substitutes alone or combined with a guided bone regeneration technique: an animal study. Int. J. Oral Maxillofac. Implants v. 13, n.1, p. 44-51, 1998. 